\title{
Volatile profiles of 47 monovarietal cloudy apple juices from commercial, old, red-fleshed and scab-resistant apple cultivars
}

\author{
Giulia Chitarrini $^{1,2} \cdot$ Valentina Lazazzara $^{1,2} \cdot$ Giuseppe Lubes $^{1,3}$. Sara Agnolet ${ }^{1,4}$. Josep Valls ${ }^{1,5}$. \\ Hildegard von Lutz ${ }^{1,6} \cdot$ Karin Brunner $^{1,7} \cdot$ Lidia Lozano $^{1,8} \cdot$ Walter Guerra ${ }^{1} \cdot$ Flavio Ciesa $^{1,9} \cdot$ Peter Robatscher $^{1}(\mathbb{D}$. \\ Michael Oberhuber ${ }^{1}$ (i)
}

Received: 5 May 2021 / Revised: 13 July 2021 / Accepted: 18 July 2021 / Published online: 4 August 2021

(c) The Author(s), under exclusive licence to Springer-Verlag GmbH Germany, part of Springer Nature 2021

\begin{abstract}
This study provides cultivar-specific metabolic fingerprints of volatile organic compounds in the headspace of cloudy apple juices. Cloudy juices from 47 "true to type" apple cultivars grown under identical agricultural and climatic conditions in South Tyrol, Italy, have been analysed through headspace solid-phase microextraction gas chromatography coupled with high-resolution time-of-flight mass spectrometry (HS-SPME/GC-HRTOF-MS), yielding cultivar-specific volatile organic compound (VOC) profiles. Apple cultivars included 10 old cultivars with local relevance, 18 commercial cultivars, dominating the current international market, 10 scab-resistant and 9 red-fleshed ones. The 28 most abundant VOCs were found in the whole dataset, indicating a remarkable chemodiversity within juices. The main discriminant metabolites were butyl acetate; pentyl acetate; 2-methylbutyl acetate; pentan-1-ol; hexan-1-ol; n-hexanal and (E)-2-hexenal. A principal component analysis (PCA) and a hierarchical cluster analysis (HCA) have not identified a clear separation of the analysed cultivar classes. Nevertheless, a series of scab-resistant and red-fleshed cultivars with VOC profiles similar to established commercial cultivars were identified; these data could help substituting current cultivars with more sustainable ones. On a more general basis, our study supports a knowledge-driven selection of apple cultivars for specific consumer preferences and helps appreciating the biodiversity of apples across old local and more recent (scab-resistant and red-fleshed) cultivars.
\end{abstract}

Keywords Apple juices $\cdot$ VOCs $\cdot$ Metabolites $\cdot$ HS-SPME/GC-HRTOF-MS

\section{Introduction}

Apple (Malus $\times$ domestica Borkh.) is one of the most important fruit crops worldwide [1]. More than 70 million tonnes of apples are produced and consumed as fresh fruit, dried, juice or alcoholic beverages. The EU's share on the apple production accounts for almost 14 million tonnes [2], with the production of approximately 2.05 billion liters of juice [3]. Darwinian evolution and a long history of breeding have generated several thousands of apple cultivars with distinct metabolic and sensory properties, but less than 100 of them are used for commercial purposes [4], and probably even less are processed to monovarietal juices. In South Tyrol, the largest contiguous apple growing area in Europe, only three cultivars (Golden Delicious, Gala and Red Delicious)

Michael Oberhuber

michael.oberhuber@laimburg.it

Extended author information available on the last page of the article account for more than $64 \%$ of the annual harvest, which corresponds to approximately $10 \%$ of the EU's apple production [5]. The remarkable but underappreciated biodiversity of apples and the associated chemodiversity of metabolites with organoleptic relevance, bear significant potential for tailoring processed products to specific consumer preferences.

Volatile organic compounds (VOCs), responsible for the aroma perception of fruits, are a major determinant of eating quality and, therefore, of consumers' buying decisions [6]. During ripening and in the postharvest chain, apples develop a complex mixture of VOCs $[7,8]$ including aldehydes, alcohols, ketones, terpenes and esters $[9,10]$. The predominant VOCs in apples and apple juices are esters and aldehydes, representing from 78 to $92 \%$ of the total volatile composition, followed by alcohols covering from 6 to $16 \%$ [11]. However, only a limited part of these compounds is recognized by the human olfactory system as the typical apple aroma [12]. Many fundamental studies on apple aroma, mostly based on gas chromatography coupled with mass 
spectrometry (GC-MS) and sensory studies, have revealed details on the aroma perception in humans, as well as the effects of ripening, storage and processing on the development of VOCs chemodiversity in various fruits [10, 13-17].

Nikfardjam et al. found 26 VOCs in 85 commercially available fresh and concentrated apple juices. For example, n-butanol, 2-methylbutan-1-ol, ethyl butanoate and ethyl-2-methylbutanoate dominated fresh juices, while $(E)$ 2-hexenal, 3-methylbutan-1-ol, ethyl acetate and n-hexanal were the most important volatiles in the concentrated ones [1]. Esters and aldehydes have a low odor threshold and give an important contribution to the typical aroma of apple juice VOCs, such as hexyl and butyl acetate, while C6 aldehydes like $(E)$-2-hexenal and n-hexanal were associated with "green-leaf" attributes [17-19].

The concentration of VOCs in apple juices is generally low and varies with agronomic and technical processing factors $[10,20]$. However, most of the studies are based on few commercially important cultivars and their juices $[12,13$, 17], and still some information is missing about the varietal differences of apple VOCs. In a similar study, Aprea et al. profiled the VOCs of 18 commercial apple cultivars using sensory analysis and solid-phase microextraction (SPME)/ GC-MS. A principal component analysis (PCA) revealed five groups of apples that can be distinguished by the content and the type of esters, as well as by the content alcohols [21]. Dunemann et al. profiled the esters of 102 apple cultivars in a genetic study to understand the diversity of acetyl ester biosynthesis [22]. In recent years, fingerprinting techniques such as electronic nose (e-nose), proton transfer reactiontime of flight-(PTR-TOF)-MS and PTR-MS combined with chemometric tools have been increasingly applied in studying apple aroma [23-25]. While these methods were successful for VOC fingerprinting $[15,26]$ and the comparison of apple cultivars [23], the identification of the compounds is based on mass only, and thus compounds with the same nominal mass cannot be distinguished. Specific studies on varietal VOC profiles are rare, but of high interest for the quality assessment of monovarietal juices. Gan et al. compared the VOCs of monovarietal clarified apple juices of five commercial cultivars using atmospheric pressure chemical ionization (APCI)-GC-MS fingerprinting. The authors identified 16 VOCs and discriminated apple juices by cultivar and geographical origin [13]. Hey et al. determinated the aroma values of 26 different apple juices [27]. Nevertheless, a comprehensive study on monovarietal cloudy juices is not available so far. In this work, we used headspace solid-phase microextraction (HS-SPME) combined with gas chromatography high-resolution time-of-flight mass spectrometry (GC-HRTOF-MS) and chemometrics to identify and compare VOCs in the headspace of 47 monovarietal cloudy apple juices from commercial, old, red-fleshed and scabresistant apple cultivars produced with standardized protocols. In our experiment we used cloudy apple juices, which contain insoluble suspended particles and fibers, appreciated for their health benefits, whereas clarified juices are obtained after filtration steps that potentially alter the flavour composition [28]. Importantly, all cultivars have been selected to cover all the cultivated apple classes in South Tyrol and were identified as 'true to type' using molecular genetic tools $[29,30]$ and grown on the same experimental field under the same growth conditions. This study will give important information for the future of the breeding programs since it includes high numbers of monovarietal cloudy apple juices of innovative pre-commercial cultivars, including red-fleshed and scab-resistant ones, some of them not previously investigated.

\section{Materials and methods}

\section{Plant and apple material}

Forty-seven apple (Malus $\times$ domestica Borkh) cultivars, including 18 commercial cultivars accounting for more than $85 \%$ of the apple production in the region [31], 10 old cultivars (known since the eighteenth century in South Tyrol), 9 red-fleshed cultivars and 10 scab-resistant ones (with monogenic resistance against Venturia inaequalis), were analysed in this study (Table 1). The cultivars were

Table 1 Apple cultivars included in this study

\begin{tabular}{|c|c|}
\hline Group & Cultivar name [Trademark name $\left.{ }^{\circledR}\right]$ \\
\hline Commercial cultivars & $\begin{array}{l}\left.\text { Braeburn, Civni [Rubens }{ }^{\circledR}\right] \text {, MC } 38 \text { [Crimson Snow }{ }^{\circledR} \text {, Elstar, Fuji, Gala, Golden Delicious, Granny Smith, Harmensz } \\
\left.\text { [Rembrandt }{ }^{\circledR}\right] \text {, Jonagold, Morgenduft, Nicoter [Kanzi®], Pinova, Red Delicious, Cripps Pink [Pink Lady }{ }^{\circledR} \text {, Scifresh } \\
\left.\left.\text { [Jazz }{ }^{\circledR}\right] \text {, Scilate [Envy }{ }^{\circledR} \text {, Shinano Gold [yello }{ }^{\circledR}\right]\end{array}$ \\
\hline Old cultivars & $\begin{array}{l}\text { Ananas Renette, Bismarkapfel, Boznerapfel, Champagner Renette, Goldparmäne, Kanada Renette, Köstlicher von } \\
\text { Zallinger, Steinpepping, Tiroler Spitzlederer, Weißer Winterkalvill }\end{array}$ \\
\hline Red-fleshed cultivars & $\begin{array}{l}\text { Bay 4583, Y103 [Kissabel®], Y102 [Kissabel®], Luregust [Calypso®/Redlove®], LUB A117/06 [Redlove®], Lure- } \\
\text { fresh [Era®/Redlove®], Luresweet [Odysso®/Redlove®], RM-1 [Red Moon®], RS-1 [Red Moon®] }\end{array}$ \\
\hline Scab-resistant cultivars & $\begin{array}{l}\left.\text { Ariane [Les Naturianes }{ }^{\circledR}\right], \text { CIV323 [Isaaq®], CIVG198 [Modí®], Fujion, Bonita, Lb 17906, Lb 8000, SQ159 } \\
\text { [Natyra }{ }^{\circledR / M a g i c ~ S t a r}{ }^{\circledR} \text { ], Topaz, UEB } 32642 \text { [Opal®] }\end{array}$ \\
\hline
\end{tabular}


accurately identified using a DNA fingerprint method based on 14 microsatellite loci $[29,30]$. To avoid potential misnaming amongst old cultivars, "true to typeness" was safeguarded by confirming their genetic profiles with accessions belonging to at least two other European germplasm collections. All apple trees were grown at Laimburg Research Centre in Auer (Ora), South Tyrol (220 m a.s.l., N 46 22' $\left.59^{\prime \prime} \mathrm{E} 11^{\circ} 17^{\prime} 18^{\prime \prime}\right)$ according to the regional guidelines for integrated fruit production in South Tyrol [32]. Apples were harvested between August and October, 2014 at their optimal harvest time to guarantee a comparable physiological state for all cultivars (Table S1). Firmness, total acidity, total sugar analysed with 'Pimprenelle' semi automatic instrument (Setop Giraud Technology, France) using 10 apples per cultivar. The starch content was determined by dipping a $1 \mathrm{~cm}$ slide of apple in an aqueous Lugol's solution $(10 \mathrm{~g} / \mathrm{L}$ $\mathrm{KI}+3 \mathrm{~g} / \mathrm{L} \mathrm{I}$ ), values expressed as mean in 10 apples using the CTIFL starch conversion. Apples were stored under atmospheric pressure at $2{ }^{\circ} \mathrm{C}$ and $90 \%$ relative humidity $(\mathrm{RH})$ for $60 \pm 10$ days. Early ripening cultivars (the ones ripening before "Gala") were stored for only 14 days to prevent senescence.

\section{Monovarietal cloudy apple juice production}

After storage, apples were immediately processed for juice making. Rotten or moldy fruits and fruits with visible damage were discarded. After washing with water at $16.8{ }^{\circ} \mathrm{C}$, apples were milled in a centrifugal mill (RM1.5, VORAN, Wels, Austria) using an 8-mm insert. About $12 \mathrm{~kg}$ of mash was collected and pressed with a hydraulically driven piston-cylinder system HP 14 (BucherUnipektin AG, Niederweningen, Switzerland). Since the fruit weight, depending on the variety, ranged from 120 to $300 \mathrm{~g} /$ fruit, around 40-100 fruits were used to produce $12 \mathrm{~kg}$ of mash. Pressing cycles were performed as follows: the first pressing step started at $2 \times 10^{5} \mathrm{~Pa}$, after $30 \mathrm{~s}$ the pressure was increased to $3 \times 10^{5} \mathrm{~Pa}$ and after other $30 \mathrm{~s}$ to $5 \times 10^{5} \mathrm{~Pa}$, followed by two additional steps at $2 \times 10^{5} \mathrm{~Pa}$ for $90 \mathrm{~s}$ each. The juice was collected and allowed to settle overnight at $4{ }^{\circ} \mathrm{C}$. Juices were pasteurized at $78-83{ }^{\circ} \mathrm{C}$ using a PA90 Voran pasteurization unit (VORAN, Wels, Austria). The hot juice was transferred to $60 \mathrm{~mL}$ amber glass vials and stored at $-80{ }^{\circ} \mathrm{C}$ until analysis.

\section{VOCs extraction: headspace solid phase microextraction (HS-SPME) of apple juices}

An automatic SPME holder equipped with a divinylbenzene/ carboxen/polydimethylsiloxane (DVB/CAR/PDMS) fiber $(50 / 30 \mu \mathrm{m}$, Supelco Co. Bellefonte, PA, USA) was used to adsorb VOCs of apple juices. The fiber was preconditioned in the needle heater of an MPS 2XL autosampler (Gerstel,
Mülheim an der Ruhr, Germany) at $270{ }^{\circ} \mathrm{C}$ for $1 \mathrm{~h}$ before analysis. An aliquot of $4950 \mu \mathrm{L}$ apple juice was transferred into an amber $20-\mathrm{mL}$ headspace vial with magnetic screw caps assembled with $1.3 \mathrm{~mm}$ Teflon-coated septa (Agilent Technologies, Santa Clara, CA, USA). An aliquot of $50 \mu \mathrm{L}$ of an aqueous solution of octan-2-ol $(5 \mathrm{mg} / \mathrm{mL})$ was added to each sample as internal standard, and $\mathrm{NaCl}$ was added to a final concentration of $200 \mathrm{~g} / \mathrm{L}$. Vials were mixed with a Vortex-Genie 2 (Scientific Industries, Bohemia, New York, USA) at $3200 \mathrm{rpm}$ for $1 \mathrm{~min}$ and incubated for $20 \mathrm{~min}$ at $40{ }^{\circ} \mathrm{C}$, then the SPME fiber was exposed to the headspace of each sample under agitation $(250 \mathrm{rpm})$ for $10 \mathrm{~min}$. The SPME fiber was transferred to the injector (Cooled Injection System, Gerstel, Mülheim an der Ruhr, Germany), and VOCs were desorbed at $250{ }^{\circ} \mathrm{C}$ for $3 \mathrm{~min}$. Three technical replicates were analysed for each apple juice and $4950 \mu \mathrm{L}$ of a saturated $\mathrm{NaCl}$ solution were used as blank to evaluate the carry over and to perform a background subtraction.

\section{GC-HRTOF-MS analysis and data analysis}

A GC 7890B (Agilent Technologies, Palo Alto, CA, USA), equipped with a Cooled Injection System (CIS) 4 inlet (Gerstel), was operated using an injector temperature of $250{ }^{\circ} \mathrm{C}$, a splitless injection mode, and a capillary column ZB-Wax ( $60 \mathrm{~m}, 0.25 \mathrm{~mm}$ i.d., $0.25 \mu \mathrm{m}$ thickness; Zebron, Phenomenex, USA) was operated at a constant pressure of helium $\left(1.0 \times 10^{5} \mathrm{~Pa}\right)$. The oven temperature consisted of $35^{\circ} \mathrm{C}$ (hold for $10 \mathrm{~min}$ ), $3{ }^{\circ} \mathrm{C} / \mathrm{min}$ to $100{ }^{\circ} \mathrm{C}, 5^{\circ} \mathrm{C} / \mathrm{min}$ to $170{ }^{\circ} \mathrm{C}$, $15^{\circ} \mathrm{C} / \mathrm{min}$ to $240^{\circ} \mathrm{C}$ (hold $15 \mathrm{~min}$ ) and the transfer line temperature was set at $250{ }^{\circ} \mathrm{C}$. The mass analyzer (LECO corporation, USA) was set to high-resolution mode with a full width at half maximum (FWHM) greater than 25,000. Data were collected in full scan mode in the mass range of $40-500 \mathrm{~m} / \mathrm{z}$, with an extraction frequency of $1.5 \mathrm{kHz}$, a scan rate of 4 scans/s, and the ionization energy of the electron impact (EI) source was set at $70 \mathrm{eV}$. ChromaTOF-HRT software version 1.81 (LECO corporation, USA), was used for data acquisition and processing. Mixed alkane standard solutions (C7-C40 n-alkanes, Sigma-Aldrich, Milan, Italy) for Kováts linear retention index (LRI) calibration were included in the sample list. VOCs were identified by: (1) matching their mass spectra against the NIST library (NIST/ EPA/NIH Mass Spectral Library, version 2.0, National Institute of Standards and Technology, Gaithersburg, MD, USA), considering those with a mass spectral match greater than 700, (2) comparing experimentally determined Kováts LRI with published LRI and (3) using commercially available authentic reference standards (Sigma-Aldrich, Milan, Italy). The abundance of each VOC was calculated as percentage peak height referred to the total height of the identified compounds. The target analyte finding (TAF) method of the 
ChromaTOF-HRT software was used to identify VOCs from apple juice samples. TAF is a feature of ChromaTOF-HRT software which enables to process comprehensive data retrospectively in a targeted manner.

\section{Data analysis and statistical processing}

TAF leverages fragment and/or molecular ions, retention times and mass tolerances to significantly reduce processing times. A TAF method was manually built using pure standards, choosing the most abundant or the discriminant ion for each compound of interest. Samples were integrated using a built method parameter evaluating the match between the detected and the reference spectra according to the following parameters: mass tolerance of $20 \mathrm{ppm}$, minimum peak eight of 50. Principal component analysis (PCA) and cluster analysis with a Euclidean distance were performed applying the R FactoMiner package using centred and scaled data [33]. The NMF R package was used for the heatmap using a log-transformed data [34]. We decided to group the apples varieties according to their genetic and cultivation properties in commercial, old, red-fleshed and scab-resistant groups.

\section{Results and discussion}

The development and composition of VOCs in apple juices is known to depend on genetic and environmental factors, including the physiological state of the fruit at harvest, storage conditions and processing methods [35]. Being aware that the pedoclimatic conditions can influence the aromatic characteristics of the apples more or less strongly we ensured the comparability of VOCs profiles, using cultivars that belonged to the Laimburg collection; they were grown on the same site under the same agricultural and climatic conditions and they were identified using molecular genetic tools.

We carefully monitored the apple characteristics at harvest to reduce the differences between cultivars. Table S1 reports firmness, total acidity, total sugar and starch content evaluated on 10 apples for variety. Since texture and firmness of fruits have a certain impact on juices yield and particularly on flavour characteristics [36-38] of the processed juices, all apples have been sampled at their optimal harvest date to preserve the varietal characteristics of each apple cultivars.

\section{HS-SPME-GC-TOF-MS analysis of VOCs in apple juices}

HS-SPME-GC-TOF-MS is a suitable analytical technique to detect VOCs in the headspace of apple juices. The volatility and the affinity of the VOCs to the SPME fiber are important factors in the compound identification [39]. Nevertheless, VOC profiles generated by SPME-GC-HRTOFMS analysis used in this study enable a highly detailed and sensitive analysis of the headspace, suitable to study varietal differences [40]. In this work, the TAF method unambiguously identified 28 most abundant VOCs (Table S2) representing six compound classes, including 17 esters, five alcohols, three aldehydes, one ketone, one phenylpropene and one terpene. Data are expressed as percentage peak height compared with the percentage of the total height of the identified compounds. To describe the complexity of apples and apple juices VOC profiles, compounds are frequently grouped into five important chemical classes, such as esters, aldehydes, alcohols, ketones and terpenes that involve distinct biochemical pathways [13, 17, 40].

Noteworthy, an accurate selection of the quantifier ion in the TAF method enabled a clear discrimination of coeluting peaks. For instance, 2-methylbutan-1-ol, and propyl butanoate co-eluted in most of the samples with common ion fragments; however, they were correctly identified using not the most abundant ions as qualifiers but the ones that are unique for each individual molecule: $\mathrm{m} / \mathrm{z} 70$ for 2-methylbutyl acetate (red peak in the extracted ion chromatogram, Figure S1) and $m / z 89$ for propyl butanoate (green peak in the extracted ion chromatogram, Figure S1) enabled to discriminate between the two peaks.

In Fig. 1 we show the data by grouping compounds by classes expressing the percentage of each class with respect to the total. Esters, aldehydes and alcohols accounted for more than $95 \%$ of the identified volatilome of all cultivars; nevertheless, their relative percentage varied significantly among varieties (Fig. 1; Table S2).

Aldehydes derive from fatty acid catabolism and branched chain amino acids, like L-valine, L-leucine and L-isoleucine, catabolism. Alcohols are assembled thanks to aldehydes reduction, catalysed by the enzyme alcohol dehydrogenase $(\mathrm{ADH})$; they are precursors of esters that are assembled by the enzyme alcohol acyltransferase (AAT) which transfers an acylic group from acyl-CoA to the hydroxy group of the alcohol [41].

In agreement with previous studies $[1,13,19]$, most esters in the apple juices' headspace ( $>80 \%$ ) were n-alkyl acetates, with hexyl and butyl acetates being the most important ones. Esters are the predominant aroma components of fresh apples and emerge during ripening and storage from C2-C8 acids and alcohols by the activity of alcohol acyltransferase (AAT) [17, 42].

In most commercial varieties included in this study, the content of esters exceeded 50\%, ranging up to $82.5 \%$ in "Scilate [Envy®]". This was expected, as breeders selected fruity and aromatic genotypes to meet consumer expectations [43]. On the other hand, Granny Smith's (Comm) volatiles were dominated by aldehydes, while "Elstar" (Comm) 


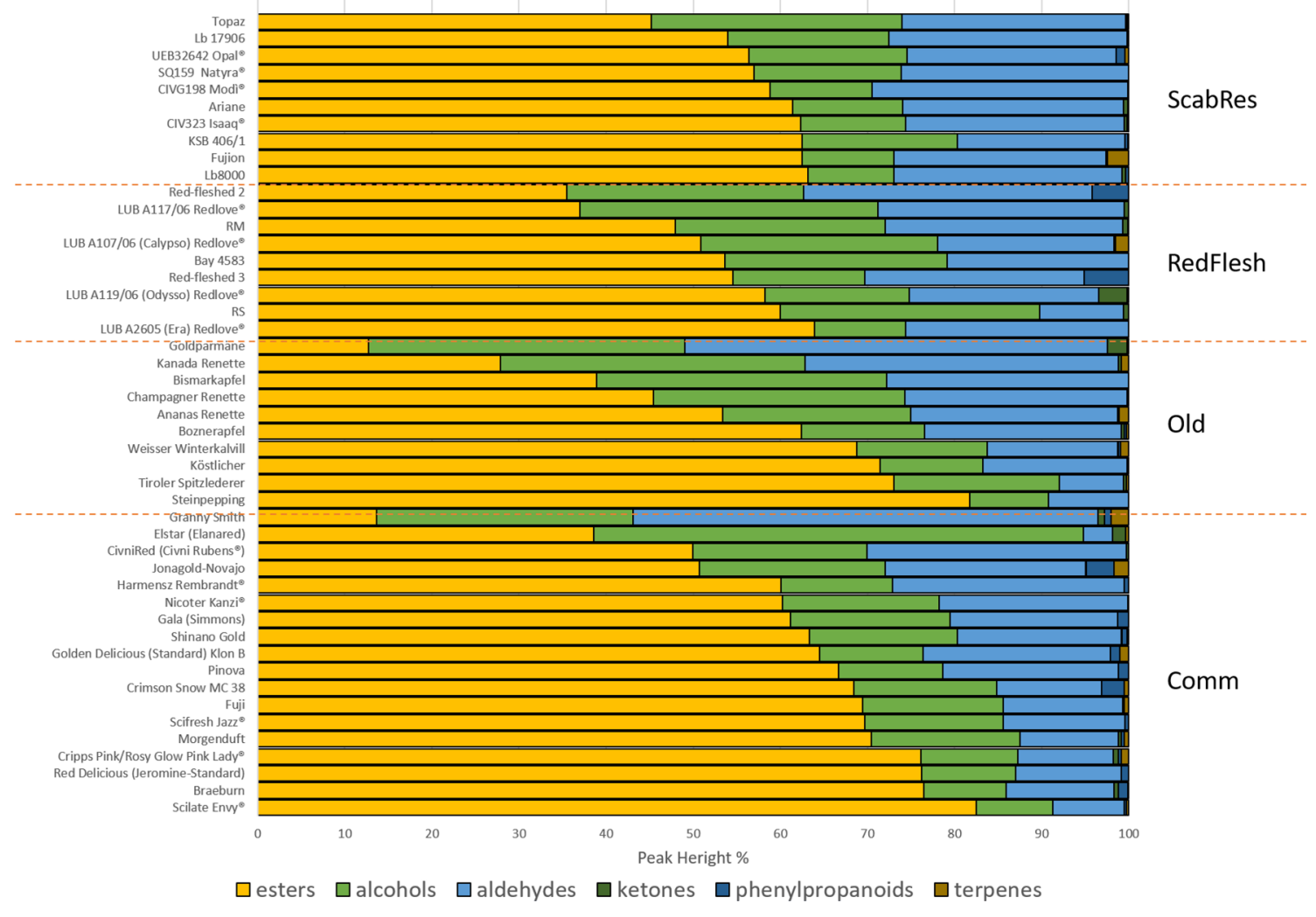

Fig. 1 Peak height percentage composition of the six classes of compounds identified in all juice samples. Data are reported by grouping compounds by classes expressing the percentage of each class with respect to the total. Data represent the average of three repli-

was characterised by a higher content of alcohols. Looking at the old cultivars, the esters' percentage varied between 12 and $81 \%$, aldehydes between 9 and $48 \%$ and alcohols between $9-36 \%$. For scab-resistant varieties, the ester content range was narrower (between 45 and 63\%) with 20-25\% aldehydes and 10-28\% alcohols. In red-fleshed varieties, esters accounted for $35-65 \%$ of the total identified volatiles, with a stronger presence of alcohols and aldehydes in their VOC profiles.

The heatmap (Fig. 2) shows the magnitude of all identified volatile compounds for each monovarietal juice with red colour representing the high-value data points and the blue colour representing the low-value data points.

The most abundant VOCs identified in this study and present in all cultivars were butyl acetate, hexanal, 2-methylbutyl acetate, hexan-1-ol and (E)-hex-2-enal (Fig. 2).

Butyl acetate has been reported by Dixon and Hewett as the most important ester in apples, along with hexyl acetate, [44]. In the commercial cultivars under study, butyl acetate represented $17-42 \%$ of the total VOCs, except for "Granny Smith" and "Civni [Rubens $\left.{ }^{\circledR}\right]$ ", where it was found only in $4.3 \%$ and $6.2 \%$, respectively. Also, in six of the ten old cultivars, butyl acetate accounted for $15-40 \%$ of the total VOCs, cates (juices from each cultivar). Cultivar names and categories are reported: ScabRes scab resistant varieties, RedFlesh red fleshed varieties, Old old varieties, Comm commercial varieties

whereas in the remaining four cultivars, it was below $15 \%$. In the red-fleshed varieties, butyl acetate was found between 2 and $47 \%$. Instead, for scab resistant varieties, the percentage does not exceed the $32 \%$ of the total VOCs.

Alcohols have been described as the second most abundant volatile chemical class in apple [45]. In our monovarietal juices, the volatile alcohols ranged from 8 to $56 \%$. Since we were not able to quantify each compound, we cannot declare their high impact on the aroma; moreover, it their high odour threshold has been reported compared to esters and aldehydes [17, 42]. We, therefore, conclude that alcohols found in this study, while being characteristic for the profile of some apple cultivars, are probably less important for their aroma. However, other experiments are required in the future to evaluate the perception of the consumers, by performing an absolute quantification of the compounds with a panel test or a GC-O test. In most juices, alcohol contents did not exceed $30 \%$ of the total volatiles, but in "Elstar", "Goldparmäne", "Kanada Renette", "LUB A117/06 [Redlove ${ }^{\circledR}$ ]" and "Bismarkapfel", the alcohol content was up to $56 \%$. As evident from the heatmap (Fig. 2) and according to the literature, hexan-1-ol and butan-1-ol are among the most prominent volatiles in apples and apple juices [46, 47]. 


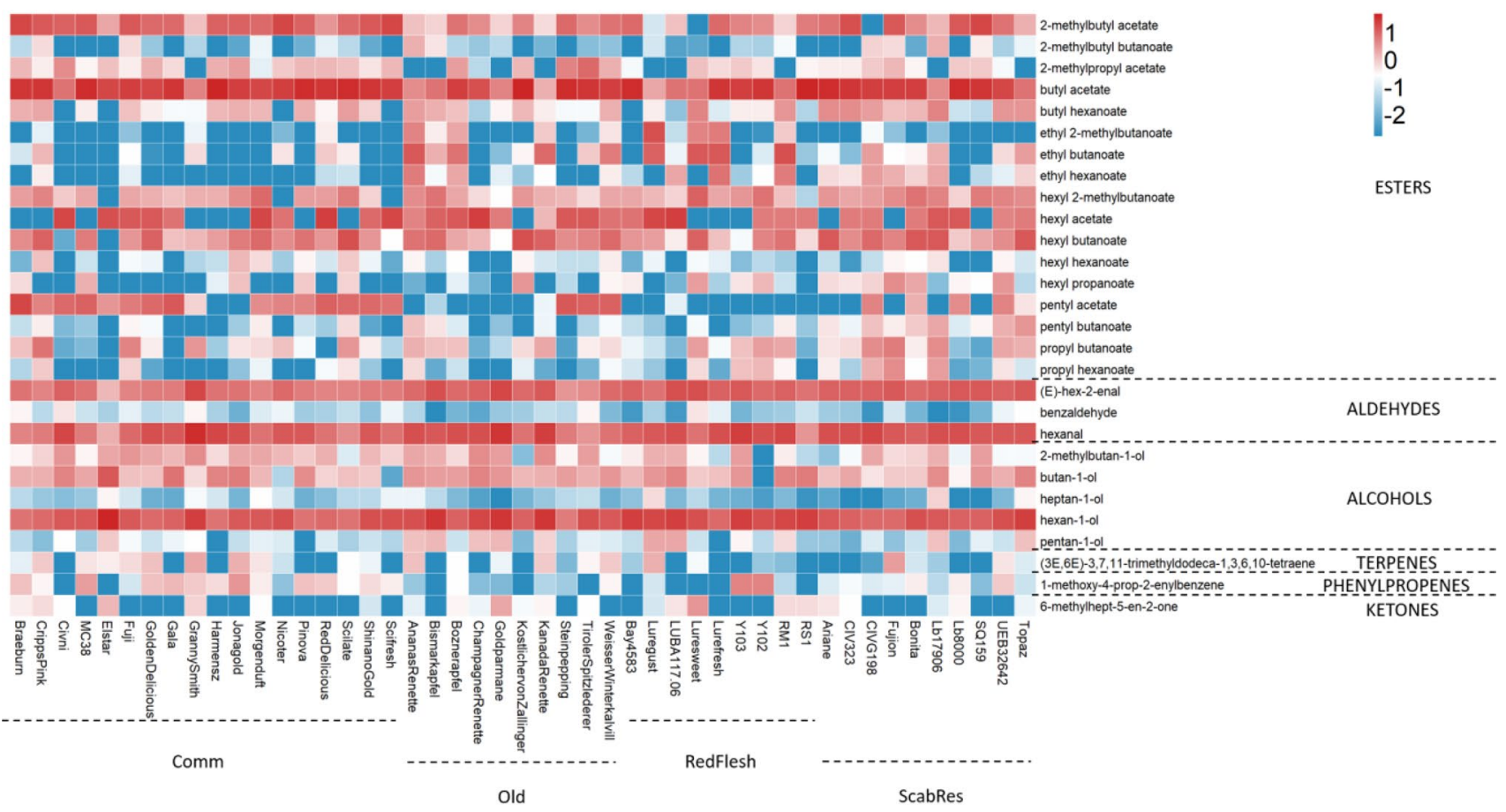

Fig. 2 Heatmap representation of the 28 most abundant volatiles identified in 47 monovarietal apple juices. Data (average of three replicates: juices from each of the analysed apple cultivars) were $\log 10$ transformed. Dark red-coloured squares indicate a high magnitude,

Only three aldehydes have been described in this study, but they represent between 3 and 53\% of the VOCs, making aldehydes the second most abundant compound class after esters. Aldehydes were consistently highly abundant in scab-resistant cultivars with $19-29 \%$ of the total identified volatiles (Fig. 1). The most abundant aldehydes were hexanal and $(E)$-hex-2-enal, described as "green" or "grassy" (Fig. 2). These aldehydes are produced primarily by the oxidation of linoleic and linolenic acids after crushing during juice production [17].

In addition, we found 6-methylhept-5-en-2-one, which does not exceed $0.5 \%$ in all cultivars except for "Luresweet [Odysso®/Redlove $\left.{ }^{\circledR}\right]$ ], "Goldparmäne" and "Elstar" with $3.2 \%, 2.2 \%$ and $1.4 \%$ of the total abundance, respectively. Among the less abundant compounds, we found 1-methoxy-4-prop-2-enylbenzene (estragole) and $(3 E, 6 E)$-3,7,11trimethyldodeca-1,3,6,10-tetraene ( $\alpha$-farnesene) which have been found in other apple cultivars [11, 17, 48]. Estragole has been found in "MC 38 [Crimson Snow $\left.{ }^{\circledR}\right]$ " $(2.6 \%)$, "Jonagold" (3.2\%), "Y103 [Kissabel $®] " ~(4.1 \%)$ and "Y102 [Kissabel $\left.{ }^{\circledR}\right] "(5 \%)$. On the other hand, $\alpha$-farnesene was found in "Luregust [Calypso®/Redlove $₫]$ " (1.5\%), "Jonagold" (1.7\%), "Granny Smith" (2\%) and "Fujion" (2.4\%). $\alpha$-Farnesene has been described with different odour dark blue-coloured squares a low magnitude. ScabRes scab resistant varieties, RedFlesh red fleshed varieties, Old old varieties, Comm commercial cultivar

perceptions such as "herbal", "green", "vegetable", "floral" or "citrus" [49].

\section{Multivariate analysis of VOCs from apple juices}

Figure 3 shows a principal component analysis (PCA) of the complete dataset scaled following the function of R Factominer package (data are scaled to unit variance), to have equal contribution of all variables not normally distributed in our experiment. The first three principal components (PCs) explained $19.2 \%, 16.8 \%$ and $8.7 \%$ of the total variance, with eigenvalues of 5.38, 4.7 and 2.4, respectively.

Neither the first and second nor the first and the third PCs made clear VOC profile clusters evident; only commercial cultivars tended to cluster together (Fig. 3A, B), especially when the first and third PCs were plotted together (Fig. 3B). The commercial cultivar "Granny Smith", known for its "green" aroma, appears not clustered with the other commercial ones and characterized for its high hexanal and (E)-hex-2-enal content (Fig. 4A, B). The commercial cultivar cluster was linked to a high abundance of esters, indeed, bi-plot analysis (Fig. 4A, B) revealed a high variable 


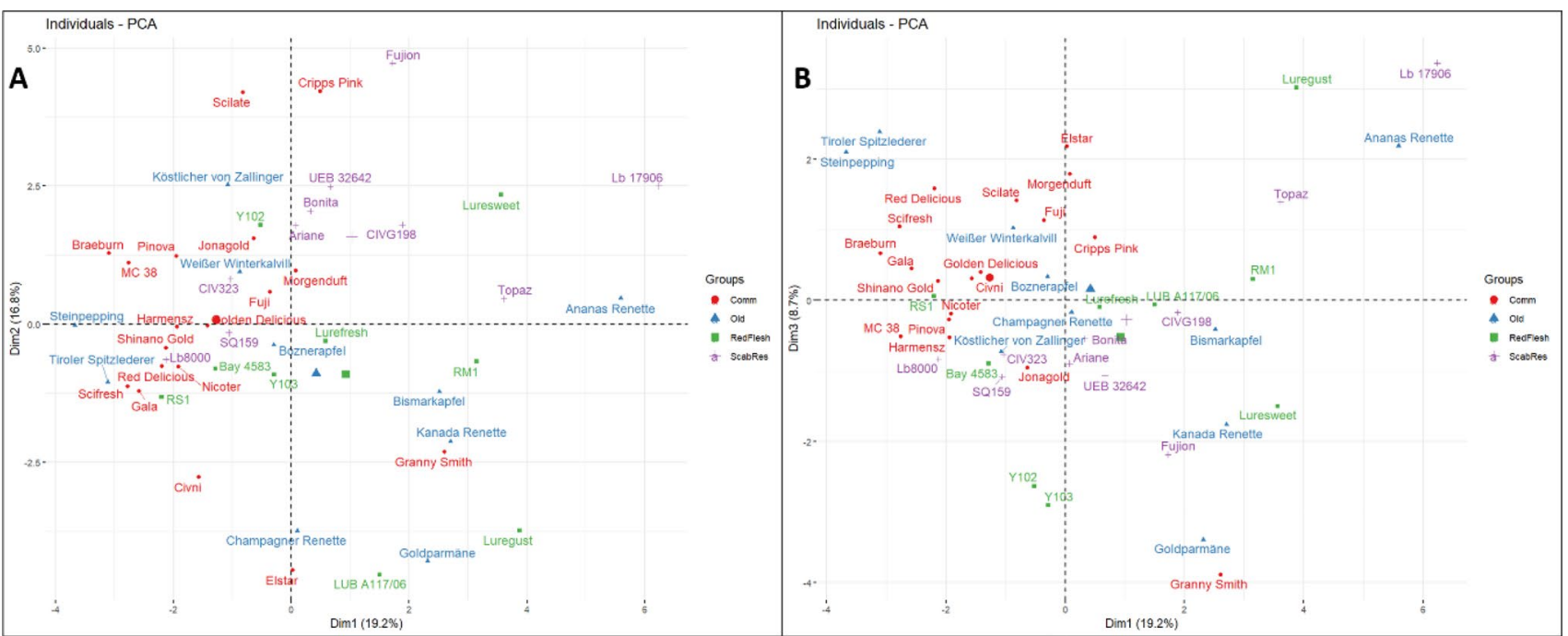

Fig. 3 Principal component analysis (PCA) of VOCs on the full dataset involving 47 monovarietal apple juices. A PC1 vs PC2; B PC1

bRes scab resistant varieties (purple), RedFlesh red-fleshed varieties vs PC3. Colours indicate apple cultivars grouped as follows: Sca-

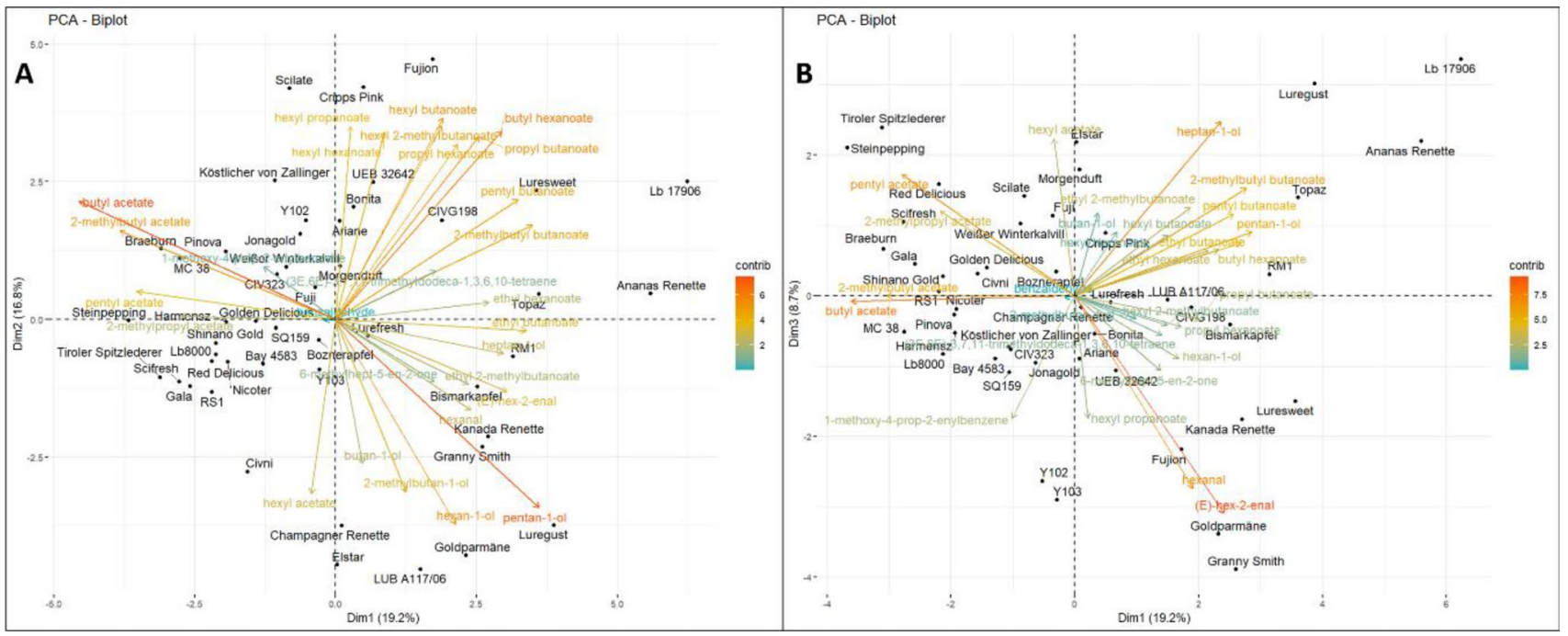

Fig. 4 Bi-plot analysis of VOCs on the full dataset involving 47 monovarietal apple juices. A PC1 vs PC2; B PC1 vs PC3. Red coloured arrows indicate a high variable contribution to the cultivars plotted; blue coloured arrows indicate a low variable contribution to the cultivars plotted

contribution of butyl acetate, pentyl acetate and 2-methylbutyl acetate to this cluster, indicating that these esters, typically linked to fruity aroma descriptors, discriminated the commercial cultivars. These findings are in accordance with previous studies $[13,17]$. The same esters negatively correlated with other VOCs, including pentan-1-ol, hexan-1-ol, 2-methylbutan-1-ol, (E)-hex-2-enal and hexanal, which are associated in literature with a "green like" aroma. Beyond the commercial cultivars, classes were not clearly separated by the PCA, suggesting that the genetic differences among commercial, old, scab-resistant and red-fleshed cultivars have limited impact on the identified compounds. A series of previous reports described cultivar-specific VOC profiles and attempted to identify individual compounds as cultivarspecific biomarkers. Gan et al. made a successful classification of five clarified monovarietal apple juices based on their ACPI-GC-MS profiles [13], identifying biomarkers in a partial least squares-discriminant analysis (PLS-DA). Reid et al. found specific VOC biomarkers to distinguish "Jonagold" from"Bramley" apple juices [50]. Some compounds like butyl acetate, (E)-hex-2-enal, 2-methyl hexyl butanoate and pentyl acetate were identified as possible biomarkers for the geographical discrimination in six monovarietal apple juices [14]. In addition, many factors, including 
the environment, maturity, storage and processing conditions affect the biosynthesis and chemical transformations of the markers and must be considered for their validation [35]. Our study, which involved 47 'true-to-type' cultivars grown and processed under identical conditions, confirmed only some of previously published biomarkers, but cultivarspecific biomarkers were not found beyond the described patterns. Nevertheless, Fig. 3 shows a remarkable chemodiversity of monovarietal apple juices, allowing producers to make a more informed choice. Despite significant progress, a deeper investigation is needed to validate these markers for cultivar identification taking into account larger datasets and different years of analysis and evaluating the compounds' absolute quantification and their aroma values.

\section{Hierarchical clustering analysis (HCA) of monovarietal cloudy apple juice VOC profiles}

To study the relationship of VOC profiles among the apple cultivars, a hierarchical cluster analysis (HCA) was performed and four main classes arose (Fig. 5). The green and blue reported clusters were dominated by the commercial cultivars that grouped together in the left-hand side of the PCA (Fig. 3A, B) and corresponded to juices whose headspace was dominated by butyl acetate, pentyl acetate and 2-methylbutyl acetate (Fig. 4A, B). The red cluster (Fig. 5), instead, contained scab-resistant and red-fleshed cultivars which were dominated by other esters (upper right-hand corner of Fig. 4A, B). The yellow cluster (Fig. 5) contained old and red-fleshed cultivars plus "Granny Smith" and "Elstar", where pentan-1-ol, hexan-1-ol, 2-methylbutan-1-ol, (E)-hex2-enal and hexanal were predominant (bottom right-hand corner of Fig. 4A, B). In line with a previous report [51], our data suggest that the discrimination of apple juices by

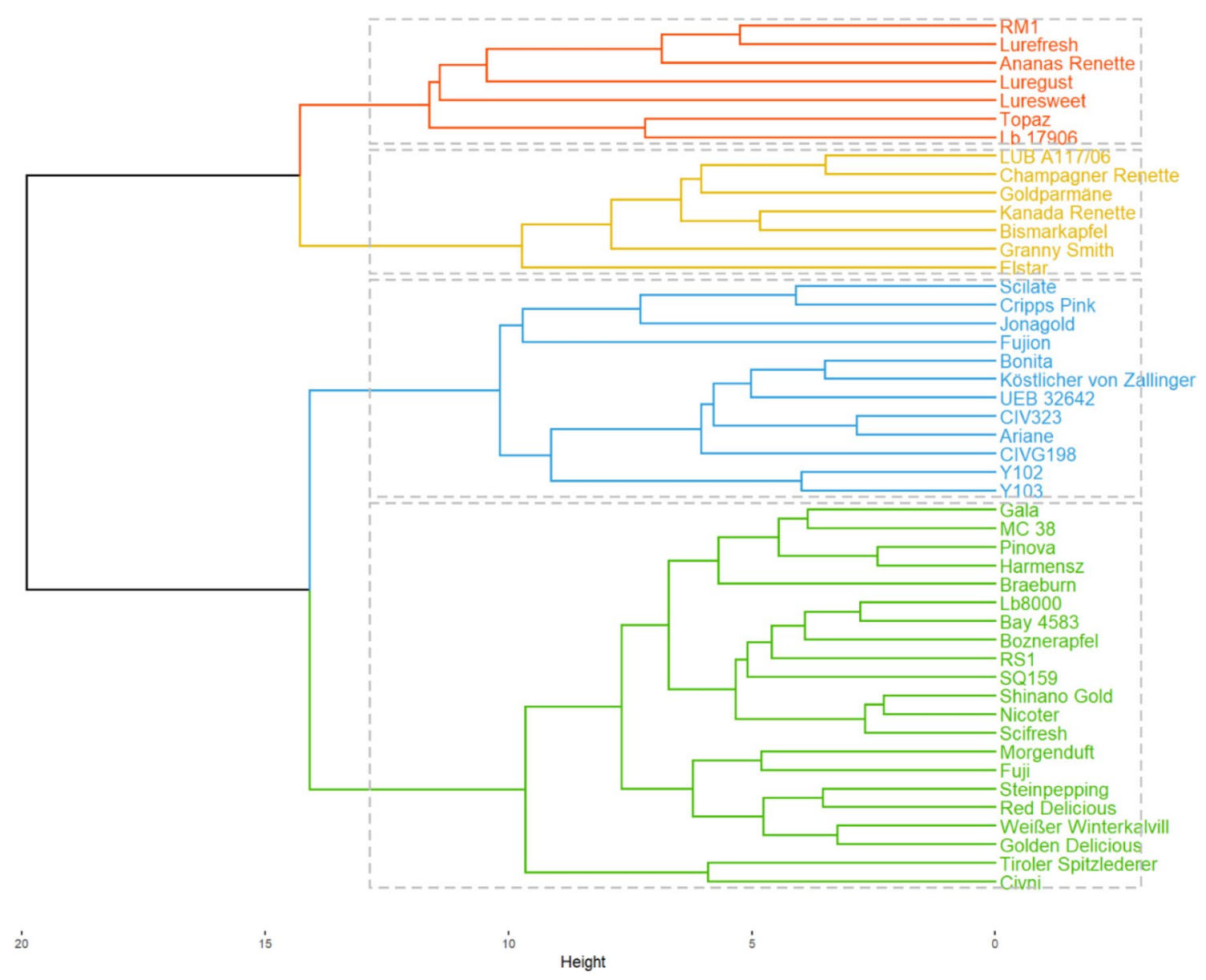

Fig. 5 Hierarchical cluster analysis (HCA) of the VOC profiles of 47 monovarietal cloudy apple juices analysed by HS-SPME/GC-HRTOFMS. The length of the horizontal line represents the diversity of cultivar VOC profiles expressed in Euclidean distance 
HCA was mainly related to the overall VOC composition and less determined by a few individual compounds. VOC profiles are helpful to compare the aroma patterns and with the further absolute quantification of the interesting compounds, to predict the possible consumer acceptance of innovative cultivars. For example, it has been reported that many scab-resistant apples are unsatisfactory in taste and in flavuor compared to top commercial varieties [52]. Our study grouped some scab-resistant ("lb 8000" and "SQ159 [Natyra $\left.{ }^{\circledR / M a g i c ~ S t a r}{ }^{\circledR}\right]$ ") as well as red-fleshed cultivars ("Bay 4583" and "RS-1 [Red Moon®]") with commercial top sellers, with a similar volatile composition. The aroma profile of these juice cultivars is more similar to the commercial juices which have a wide consensus among consumers. Another noteworthy observation is that "Granny Smith" and "Elstar" were clustered with old and red-fleshed cultivars, but not with the other commercial cultivars, as in our previous study, where Ciesa et al. [23] used proton transfer reaction mass spectrometry (PTR-MS) to compare VOC profiles of 42 apple cultivars, 17 of which were also included in this study. Even though with PTR-MS individual compounds could not be identified, a PCA indicated a separation of cultivars due to differences in (acetate) ester and terpene contents [23].

While the ester differences clearly emerged from the present study, differences on terpene ( $\alpha$-farnesene) content was less evident here. "Red Delicious" were previously reported in a separate branch of the cluster and identified as cultivar with different aroma profile, compared to the commercial ones [23]. Instead, in our work "Red Delicious" is included in the commercial cluster after HCA and projected in the same PCA direction (Figs. 3, 5). Apparently, the two approaches highlight complementary differences in cultivarspecific apple profiles with some similar results in both studies [23], indicating that a synergic analysis including both HS-SPME/GC-HRTOF-MS and PTR-MS methodologies should be performed in order to have a clearer interpretation of VOCs profile of apple juices from different cultivars.

\section{Conclusions}

The diversity of apple cultivars provides an underused resource for tailoring apples juices to consumer preferences. The aroma of apple juice is determined by a complex mixture of VOCs of different classes and odor thresholds. To study the contribution of VOCs to apple cultivars, we prepared 47 monovarietal apple juices under standardized conditions and we measured their VOC profiles.

While consistent knowledge is available on the VOCs composition of commercial and South Tyroleans apples and apple juices, this study took into consideration both old and new apple cultivars and described comprehensively the volatile composition of pre-commercial red-fleshed cultivars for the first time.

Our SPME/GC-HRTOF-MS approach focused on comparing monovarietal apple juice VOC profiles to identify potential cultivars for specific consumer preferences. By investigating the different juice cultivare we notice a large variability within each group and a not clear separation of our groups using a multivariate analysis. Through the PCAs and the hierarchical clusterization our results highlighted that some scab-resistant and red-fleshed cultivar have a similar VOC profiles as a commercial one when grown under the same conditions, in detail "lb 8000" and "SQ159 [Natyra ${ }^{\circledR /}$

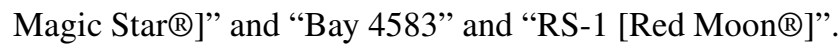
These results provide a basis of tailoring apple derivatives for specific consumer preferences and improve the acceptance of scab-resistant and red-fleshed cultivars. Further studies are needed to better discriminate apple cultivars based on their juices and to deeper understand the genetic background of the detected VOC diversity in order to foster the genetic potential of thousands of apple cultivars in breeding programs aimed at aromatic profiles that meet the expectations of consumers worldwide.

Supplementary Information The online version contains supplementary material available at https://doi.org/10.1007/s00217-021-03826-7.

Acknowledgements Matthias Siller, Vill Hannes, Gadotti Cristina and Hanna Bürgschwendter are gratefully acknowledged for administrative support.

Funding Financial support by the European Regional Development Fund Program (Project POMOSANO Nr. 5-1a-238 CUP: H21J12000060001 and Project LAGREIN Nr. 4-1a-168 CUP: H21J11000020006) and by the Autonomous Province of Bolzano. Laimburg Research Centre is funded by the Autonomous Province of Bozen-Bolzano.

\section{Declarations}

Conflict of interest The authors declare no conflict of interest.

Compliance with ethics requirements This article does not contain any studies with human or animal subjects.

\section{References}

1. Nikfardjam MP, Maier D (2011) Development of a headspace trap HRGC/MS method for the assessment of the relevance of certain aroma compounds on the sensorial characteristics of commercial apple juice. Food Chem 126:1926-1933. https://doi.org/10.1016/j. foodchem.2010.12.021

2. FAOSTAT (2020) Apple production in 2018; Crops/World Regions/Production Quantity; Food and Agriculture Organization of the United Nations

3. Statista (2020) Production volume of apple juice in the European Union (EU) from 2008 to 2017. The statistic portal 
4. Elzebroek ATG (2008) Guide to cultivated plants. CABI

5. Autonomous Province of Bozen (2020) Agricultural and forestry report 2018

6. Karlsen AM, Aaby K, Siversten H, Baardseth P, Ellekjser MR (1999) Instrumental and sensory analysis of fresh Norwegian and imported apples. Food Qual Prefer 10:305

7. Kader AA (2008) Perdpective flavor quality of fruits and vegetables. J Sci Food Agric 88:1863-1868. https://doi.org/10.1002/jsfa. 3293

8. Harker F, Gunson F, Jaeger SR (2003) The case for fruit quality: an interpretive review of consumer attitudes, and preferences for apples. Postharvest Biol Technol 28:333-347. https://doi.org/10. 1016/S0925-5214(02)00215-6

9. Rothe M (1991) Volatile compounds in foods and beverages. Maarse, New York

10. Dimick PS, Hoskin JC (1983) Review of apple flavor-state of the art. CRC Crit Rev Food Sci Nutr 18:387

11. Paillard NMM (1990) The flavour of apples, pears and quinces. Food flavours, Part C: The flavour of fruits

12. Mehinagic E, Royer G, Symoneaux R, Jourjon F, Prost C (2006) Characterization of odor-active volatiles in apples: influence of cultivars and maturity stage. J Agric Food Chem 54:2678-2687. https://doi.org/10.1021/jf052288n

13. Gan H-H, Soukoulis C, Fisk I (2014) Atmospheric pressure chemical ionisation mass spectrometry analysis linked with chemometrics for food classification - a case study: geographical provenance and cultivar classification of monovarietal clarified apple juices. Food Chem 146:149-156. https://doi.org/10.1016/j.foodchem. 2013.09.024

14. Guo J, Yue T, Yuan Y (2012) Feature selection and recognition from nonspecific volatile profiles for discrimination of apple juices according to variety and geographical origin. J Food Sci 77:C1090-C1096. https://doi.org/10.1111/j.1750-3841.2012. 02914.x

15. Ciesa F, Dalla Via J, Wisthaler A, Zanella A, Guerra W, Mikoviny T, Märk TD, Oberhuber M (2013) Discrimination of four different postharvest treatments of 'Red Delicious' apples based on their volatile organic compound (VOC) emissions during shelf-life measured by proton transfer reaction mass spectrometry (PTRMS). Postharvest Biol Technol 86:329-336. https://doi.org/10. 1016/j.postharvbio.2013.06.036

16. Schulz I, Ulrich D, Fischer C (2003) Rapid differentiation of new apple cultivars by headspace solid-phase microextraction in combination with chemometrical data processing. Food 47:136

17. Dixon J, Hewett EW (2000) Factors affecting apple aroma/flavour volatile concentration: a review. N Z J Crop Hortic Sci 28:155

18. Zheng CH, Kim TH, Kim KH, Leem YH, Lee HJ (2004) Characterization of potent aroma compounds inChrysanthemum coronarium L. (Garland) using aroma extract dilution analysis. Flavour Fragr J 19:401-405. https://doi.org/10.1002/ffj.1447

19. Komthong P, Igura N, Shimoda M (2007) Effect of ascorbic acid on the odours of cloudy apple juice. Food Chem 100:1342

20. Su SK, Wiley RC (1998) Changes in apple juice flavor compounds during processing. J Food Sci 63(4):688-691. https://doi.org/10. 1111/j.1365-2621.1998.tb15813.x

21. Aprea E, Corollaro ML, Betta E, Endrizzi I, Demattè ML, Biasioli F, Gasperi F (2012) Sensory and instrumental profiling of 18 apple cultivars to investigate the relation between perceived quality and odour and flavour. Food Res Int 49:677-686. https:// doi.org/10.1016/j.foodres.2012.09.023

22. Dunemann F, Ulrich D, Malysheva-Otto L, Weber WE, Longhi S, Velasco R, Costa F (2012) Functional allelic diversity of the apple alcohol acyl-transferase gene MdAAT1 associated with fruit ester volatile contents in apple cultivars. Mol Breed 29:609-625. https://doi.org/10.1007/s11032-011-9577-7
23. Ciesa F, Holler I, Guerra W, Berger J, Dalla Via J, Oberhuber M (2015) Chemodiversity in the fingerprint analysis of volatile organic compounds (VOCs)of35 old and 7 modern apple cultivars determined by proton-transfer-reaction mass spectrometry (PTRMS) in two different seasons. Chem Biodivers 12:800

24. Marrazzo WN, Heinemann PH, Crassweller RE, LeBlanc E (2005) Electronic nose chemical sensor feasibility study for the differentiation of apple cultivars. Transac ASAE 48:199

25. Farneti B, Khomenko I, Cappellin L, Ting V, Costa G, Biasioli F, Costa F (2015) Dynamic volatile organic compound fingerprinting of apple fruit during processing. LWT-Food Sci Technol 63:21

26. Biasioli F, Gasperi F, Yeretzian C, Märk TD (2011) PTR-MS monitoring of VOCs and BVOCs in food science and technology. TrAC Trends Anal Chem 30:968-977. https://doi.org/10.1016/j. trac.2011.03.009

27. Hey M, Kürbel P, Hopf I, Dietrich H (2007) Untersuchung sortenreiner Apfelsaftaromen. Flüssiges Obst 02:62-67

28. Zhu D, Shen Y, Wei L, Xu L, Xuehui C, Liu H, Li J (2020) Effect of particle size on the stability and flavour of cloudy apple juice. Food Chem. https://doi.org/10.1016/j.foodchem.2020.126967

29. Baric S, Storti A, Hofer M, Dalla Via J (2009) Molecular genetic characterisation of apple cultivars from different germplasm collections. Acta Horticulturae

30. Baric S, Storti A, Hofer M, Guerra W, Via JD (2020) Genetic identification of apple cultivars based on microsatellite DNA analysis. I. The database of 600 validated profiles. Erwerbs-obstbau 62:1-38

31. Dalla VJ, Mantinger H (2012) Agricultural research in the field of fruit growing in South Tyrol. Erwerb-Obstbau 54:83-115

32. AGRIOS (2014) Guidelines for Integrated Pome Cultivation 2014. AGRIOS, Workgroup for Integrated Fruit Production in South Tyrol, Italy

33. Le S, Josse J, Husson F (2008) FactoMineR: an R package for multivariate analysis. J Stat Softw 25:1-18

34. Gaujoux R, Seoiche C (2010) A flexible R package for nonnegative matrix Open Access factorization. BMC Bioinform 11:1

35. Eisele TA, Drake SR (2005) The partial compositional characteristics of apple juice from 175 apple varieties. J Food Compos Anal 18:213-221. https://doi.org/10.1016/j.jfca.2004.01.002

36. Danshi Z, Chengcheng K, Yusi S, Pushun X, Xuehui C, He L, Jianrong L (2021) Effects of different processing steps on the flavor and colloidal properties of cloudy apple juice. J Sci Food Agric 101:3819-3826. https://doi.org/10.1002/jsfa.11016

37. Knoop JE, Sala G, Smit G, Stieger M (2013) Combinatory effects of texture and aroma modification on taste perception of model gels. Chemosens Percept 6:60-69

38. Reis S, Rocha SM, Barros AS, Delgadillo I, Coimbra MA (2009) Establishment of the volatile profile of 'bravo de Esmolfe' apple variety and identification of varietal markers. Food Chem 113:513-521

39. Rocha S, Ramalheira V, Barros A, Delgadillo I, Coimbra MA (2001) Headspace solid phase microextraction (SPME) analysis of flavor compounds in wines. Effect of the matrix volatile composition in the relative response factors in a wine model. J Agric Food Chem 49:5142-5151. https://doi.org/10.1021/jf010566m

40. El Hadi M, Zhang F-J, Wu F-F, Zhou C-H, Tao J (2013) Advances in fruit aroma volatile research. Molecules 18:8200-8229. https:// doi.org/10.3390/molecules18078200

41. De Filippi BG, Kader AA, Dandekar AM (2005) Apple aroma: alcohol acyltransferase, a rate limiting step for ester biosynthesis, is regulated by ethylene. Plant Sci 168:1199-1210. https://doi.org/ 10.1016/j.plantsci.2004.12.018

42. Echeverria G, Fuentes T, Graell J, Lara I, López ML (2004) Aroma volatile compounds of 'Fuji' apples in relation to harvest date and cold storage technology: a comparison of two seasons. Postharvest Biol Technol 32:29 
43. Brown SK, Maloney KE (2009) Making sense of new apple varieties, trademarks and clubs: current status. N Y Fruit Q 17:9

44. Dixon J, Hewett EW (2000) Factors affecting apple aroma/flavour volatile concentration: a review. N Z J Crop Hortic Sci. https://doi. org/10.1080/01140671.2000.9514136

45. Vrhovsek U, Lotti C, Masuero D, Carlin S, Weingart G, Mattivi F (2014) Quantitative metabolic profiling of grape, apple and raspberry volatile compounds (VOCs) using a GC/MS/MS method. J Chromatogr B Analyt Technol Biomed Life Sci 966:132-139. https://doi.org/10.1016/j.jchromb.2014.01.009

46. Steinhaus M, Bogen J, Schieberle P (2006) Key aroma compounds in apple juice-changes during juice concentration. Dev Food Sci 43:189-192. https://doi.org/10.1016/S0167-4501(06)80045-2

47. Espino-Díaz M, Sepúlveda DR, González-Aguilar G, Olivas GI (2016) Biochemistry of apple aroma: a review. Food Technol Biotechnol 54:375

48. Mattheis JP, Buchanan DA, Fellman JK (1998) Volatile compounds emitted by 'Gala' apples following dynamic atmosphere storage. J Amer Soc Hort Sci 123:426

49. The goodscents company. Available online: http://www.thego odscentscompany.com/.
50. Reid LM, O’Donnell CP, Kelly JD, Downey G (2004) Preliminary studies for the differentiation of apple juice samples by chemometric analysis of solid-phase microextraction-gas chromatographic data. J Agric Food Chem 52:6891-6896. https://doi.org/10.1021/ jf0491431

51. González-Mas MC, Rambla JL, Alamar MC, Gutiérrez A, Granell A (2011) Comparative analysis of the volatile fraction of fruit juice from different Citrus species. PLoS ONE 6:e22016. https:// doi.org/10.1371/journal.pone.0022016

52. Dunemann F, Ulrich D, Boudichevskaia A, Grafe C, Weber WE (2009) QTL mapping of aroma compounds analysed by headspace solid-phase microextraction gas chromatography in the apple progeny 'Discovery' $\times$ 'Prima.' Mol Breeding 23:501-521. https://doi.org/10.1007/s11032-008-9252-9

Publisher's Note Springer Nature remains neutral with regard to jurisdictional claims in published maps and institutional affiliations.

\title{
Authors and Affiliations
}

\author{
Giulia Chitarrini $^{1,2} \cdot$ Valentina Lazazzara $^{1,2} \cdot$ Giuseppe Lubes $^{1,3} \cdot$ Sara Agnolet ${ }^{1,4} \cdot$ Josep Valls $^{1,5}$. \\ Hildegard von Lutz ${ }^{1,6} \cdot$ Karin Brunner $^{1,7} \cdot$ Lidia Lozano $^{1,8}$. Walter Guerra ${ }^{1} \cdot$ Flavio Ciesa $^{1,9} \cdot$ Peter Robatscher $^{1}$ (D) \\ Michael Oberhuber ${ }^{1}$ (1) \\ Giulia Chitarrini \\ giulia.chitarrini@laimburg.it \\ Valentina Lazazzara \\ valentina.lazazzara@fmach.it \\ Giuseppe Lubes \\ giuseppelubes@gmail.com \\ Sara Agnolet \\ sara.agnolet@gmail.com \\ Josep Valls \\ josep.valls-fonayet@u-bordeaux.fr \\ Hildegard von Lutz \\ hildegard@ vonlutz.it \\ Karin Brunner \\ Karin.brunner@darbo.at \\ Lidia Lozano \\ lidialozano.31@gmail.com \\ Walter Guerra \\ walter.guerra@laimburg.it \\ Flavio Ciesa \\ flavio.ciesa@provincia.bz.it \\ Peter Robatscher \\ peter.robatscher@laimburg.it \\ 2 Present Address: Research and Innovation Centre, \\ Fondazione Edmund Mach, Via E. Mach 1, \\ 38098 San Michele all'Adige, Italy \\ 3 Present Address: Laboratorio de Equilibrios en Solución, \\ Departamento de Química, Universidad Simón Bolívar \\ (USB), Caracas, Venezuela \\ 4 Present Address: Analytical Chemistry Group, Department \\ of Plant and Environmental Sciences, University \\ of Copenhagen, Thorvaldsensvej 40, 1871 Frederiksberg, \\ Denmark \\ 5 Present Address: Unité de Recherche Oenologie, Axe \\ Molécules d'Intérêt Biologique, EA 4577, USC 1366 \\ INRAE, ISVV, Université de Bordeaux, 210, Chemin de \\ Leysotte, F-33882 Villenave d'Ornon, France \\ 6 Present Address: Fruitservice GmbH / Srl, Boznerstraße 63 \\ (Via Bolzano), IT- 39057 Frangart (Frangarto), Italy \\ 7 Present Address: A. Darbo AG, Werk Fruchtzubereitung, Am \\ Rain 273, 6135 Stans/Tirol, Austria \\ 8 Present Address: IRTA Fruitcentre, PCiTAL, Park \\ of Gardeny, Fruitcentre Building, 25003 Lleida, Spain \\ 9 Present Address: Laboratory of Food Analysis, \\ Provincial Environment Agency, Via Amba Alagi 5, \\ 39100 Bozen/Bolzano, Italy
}

1 Laimburg Research Centre, Laimburg 6 - Pfatten (Vadena), IT-39040 Auer (Ora), Italy 